\title{
Hepatocyte Growth Factor/Scatter Factor Is a Neurotrophic Survival Factor for Lumbar But Not for Other Somatic Motoneurons in the Chick Embryo
}

\author{
Kristine D. Novak, David Prevette, Siwei Wang, Tom W. Gould, and Ronald W. Oppenheim \\ Department of Neurobiology and Anatomy and the Neuroscience Program, Wake Forest University School of Medicine, \\ Winston-Salem, North Carolina 27157
}

\begin{abstract}
Hepatocyte growth factor/scatter factor (HGF/SF) is expressed in the developing limb muscles of the chick embryo during the period of spinal motoneuron (MN) programmed cell death, and its receptor C-met is expressed in lumbar MNs during this same period. Although cultured motoneurons from brachial, thoracic, and lumbar segments are all rescued from cell death by chick embryo muscle extract (CMX) as well as by other specific trophic agents, HGF/SF only promotes the survival of lumbar MNs. Similarly, treatment of embryos in ovo with exogenous HGF/SF rescues lumbar but not other somatic MNs from cell
\end{abstract}

It has long been recognized that MNs in the spinal cord and brainstem can be distinguished at the cellular level by the location of their cell bodies in the CNS (e.g., a motor pool) and by their peripheral target projections. Although somatic MNs appear homogenous by a number of criteria (e.g., cholinergic phenotype, innervation of skeletal muscle, etc.), their diversity at the cellular level provides a beginning framework for defining the mechanisms that control the diversification of this single class of CNS neurons (Pfaff and Kitner, 1998).

Within the spinal cord, motor neuron (MN) subtypes are located in more or less discrete columns that may span a few or several segments and that have relatively stereotyped rostralcaudal, dorsal-ventral, and medial-lateral positions. Additionally, MNs that share projection pathways to specific muscle groups (e.g., to the dorsal musculature of a limb) colocalize into columns, and within columns, subclasses of MNs that innervate a specific target muscle (e.g., the gastrocnemius) comprise a cluster of MN cell bodies, the motor pool (Landmesser, 1978; Oppenheim, 1981; Hollyday, 1990).

Recent studies have identified a number of genes that are differentially expressed in subpopulations of early developing MNs and likely to contribute to MN specialization. One major class of genes is the Islet family of LIM homeobox transcription factors that can also serve as molecular markers for MN subtypes. These markers appear early in development (Tsuchida et al.,

Received May 3, 1999; revised Sept. 20, 1999; accepted Oct. 19, 1999.

This work was supported by National Institutes of Health Grants NS20402 (R.W.O.) and NS10538 (K.D.N.). We thank Carol FloresDeValgaz for technical help; Claudio Stern for sharing chicken probes for HGF/SF and c-met and for the kind gift of rcHGF/SF; and Amgen (BDNF, CNTF) and Genentech (GDNF, $\mathrm{HGF} / \mathrm{SF}$ ) for the generous gifts of recombinant human neurotrophic factors.

Correspondence should be addressed to Ronald W. Oppenheim, Department of Neurobiology and Anatomy, Wake Forest University School of Medicine, Medical Center Boulevard, Winston-Salem, NC 27157-1010. E-mail: roppenhm@ wfubmc.edu.

Copyright (C) 1999 Society for Neuroscience $\quad 0270-6474 / 99 / 200326-12 \$ 15.00 / 0$ death. Blocking antibodies to HGF/SF (anti-HGF) reduce the effects of CMX on MN survival in vitro and decrease the number of lumbar MNs in vivo. The expression of c-met on MNs in vivo is regulated by a limb-derived trophic signal distinct from HGF/ SF. HGF/SF is a potent, select, and physiologically relevant survival factor for a subpopulation of developing spinal MNs in the lumbar segments of the chick embryo.

Key words: cell death; motoneurons; HGF/SF; chick embryo; spinal cord; trophic factor

1994; Tokumoto et al., 1995)and are initiated by inductive signals from paraxial mesoderm and by interactions between migrating MN subtypes, before the projection of MN axons to their target muscles (Matise and Lance-Jones, 1996; Tanabe and Jessell, 1996; Ensini et al., 1998; Sockanathan and Jessell, 1998). From these and related studies, a general program of MN specification is being revealed in which sonic hedgehog signals derived from notochord and floorplate induce a generic ventral $\mathrm{MN}$ phenotype that is then followed by specification of $\mathrm{MN}$ subtypes that reflect their position within the spinal cord, peripheral projection pathways, and choice of synaptic targets (Pfaff and Kitner, 1998).

Once MNs begin to innervate their appropriate muscle targets, a period of programmed cell death (PCD) ensues during which approximately one-half of the neurons of each subtype degenerate by a genetically regulated program of apoptosis (Oppenheim, 1991, 1998; Henderson, 1998). The decision to live or die appears to be initiated by competition between MNs for target as well as for non-target-derived sources of neurotrophic molecules (Nishi, 1994; Burek and Oppenheim, 1998). Although a large number of trophic factors comprising several distinct gene families have been shown to promote MN survival in vitro and in vivo (Arakawa et al., 1990; Hughes et al., 1993; Oppenheim et al., 1993; Henderson, 1996; Oppenheim, 1996; Zurn et al., 1996; Hanson et al., 1998), it has generally been assumed that regardless of the $\mathrm{MN}$ subtype all somatic MNs in the brainstem and spinal cord have the same trophic requirements. That is, cranial, cervical, thoracic, and lumbar MNs, for example, as well as MN subtypes within a region (e.g., all motor pools in the lumbar region), were thought to share responsiveness to particular trophic factors. Notwithstanding previous assumptions on this matter, however, evidence from peripheral sensory neurons is not consistent with this idea and, in fact, provides compelling support for distinct trophic requirements of sensory neuron subtypes based on functional and other phenotypic characteristics (Mu et al., 1993; Snider, 1994; Oakley et al., 1997). Additionally, the molecular diversity of MNs 
at stages before the onset of PCD (e.g., LIM/Islet expression) suggests that a similar diversity may exist in the later trophic requirements of MNs. Although previous observations have also provided evidence that does not support the idea of homogeneous trophic support for all MNs (Oppenheim et al., 1993; Johnson et al., 1995), until very recently there have been no systematic attempts to directly test this notion or to determine whether in fact $\mathrm{MN}$ subtypes have distinct trophic requirements.

$\mathrm{HGF} / \mathrm{SF}$ is a $90 \mathrm{kDa}$ heterodimeric protein that is structurally similar to plasminogen but does not have enzymatic activity (Nakamura et al., 1989; Weidner et al., 1993). The only known receptor for $\mathrm{HGF} / \mathrm{SF}$ is the tyrosine receptor kinase c-met, and recent studies have shown that $\mathrm{HGF} / \mathrm{SF}-\mathrm{c}-\mathrm{met}$ interaction elicits a complex set of signal transduction pathways. HGF/SF has been identified as a mitogen for mature hepatocytes and was subsequently shown to be a morphogen and mitogen for renal tubules, epithelia cells, keratinocytes, meleanocytes, and pancreatic B cells, as well as an angiogenic factor, an inducer of osteoblastic differentiation, and a stimulant of migration and invasion by various types of carcinoma cells (Matsumoto and Nakamura, 1997; Birchmeier and Gherardi, 1998; Maina and Klein, 1999). $\mathrm{HGF} / \mathrm{SF}$ has also been implicated in sensory and sympathetic neuron development, acting synergistically with NGF to enhance axonal outgrowth and survival of mammalian DRG neurons (Maina et al., 1997) and as an autocrine factor for axonal outgrowth of sympathetic neurons (Yang et al., 1998). Recently, $\mathrm{HGF} / \mathrm{SF}$ was also shown to be a diffusible limb-derived MN chemoattractant (Ebens et al., 1996) as well as a trophic factor for cultured rat MNs (Ebens et al., 1996; Wong et al., 1997; Yamamoto et al., 1997) and dopaminergic neurons (Hamanoue et al., 1996). The study by Yamamoto et al. (1997) is of particular interest in that they report that $\mathrm{HGF} / \mathrm{SF}$ is a potent survival factor for cultured rat limb-innervating MNs but only weakly supports the survival of non-limb (thoracic) MNs. Using in situ hybridization, they report that c-met is only expressed in limb-innervating MNs. In the present study, we have examined the role of $\mathrm{HGF} / \mathrm{SF}$ in the survival of chick embryo MNs in vitro and in vivo and show for the first time that $\mathrm{HGF} / \mathrm{SF}$ promotes the in vivo survival of subpopulations of spinal MNs.

Portions of this work have appeared previously in abstract form (Prevette et al., 1997).

\section{MATERIALS AND METHODS}

In vitro motoneuron cultures. Motoneurons were isolated from stage 27-28 [embryonic day 5.0 (E5.0)] chick embryos as determined by the staging criteria of Hamburger and Hamilton (1951). Briefly, the ventral portion of the lumbar, thoracic, or brachial region of the spinal cord was removed by dissection using tungsten needles. Ventral spinal cords were then treated with trypsin $[0.25 \%$ in PBS (Life Technologies, Gaithersburg, MD)] for $15 \mathrm{~min}$, and the tissue was dissociated by passing it several times through a $1.0 \mathrm{ml}$ pipette tip. The cell suspension was layered onto a $6.8 \%$ metrizamide (Serva, Heidelberg, Germany) cushion and centrifuged at $1600 \mathrm{rpm}$. The cell layer at the top of the metrizamide, containing predominantly large MNs and forming a visible white band, was collected and added to $5 \mathrm{ml}$ of media. BSA (4\%) was then gently added beneath the cell suspension and centrifuged at $1000 \mathrm{rpm}$ for 10 min. Once the supernatant was discarded, the pellet was then resuspended in $1 \mathrm{ml}$ media and filtered through a $50 \mu \mathrm{M}$ nylon filter. A portion of this preparation was loaded onto a hemocytometer for an initial cell count. From this initial count the cells were diluted appropriately and plated in $35 \mathrm{~mm}$ Petri dishes, each with four wells, $10 \mathrm{~mm}$ in diameter [greiner dishes (Bellco)], which were precoated with polyornithine (1 $\mu \mathrm{g} / \mathrm{ml}$; Sigma, St. Louis, MO) and laminin $(20 \mu \mathrm{g} / \mathrm{ml}$; Life Technologies). A serum-free culture medium containing Leibovitz's L15 media (Life Technologies) supplemented with sodium bicarbonate $(625 \mu \mathrm{g} / \mathrm{ml})$, glucose $(20 \mathrm{~mm})$, progesterone $\left(2 \times 10^{-8} \mathrm{M}\right.$; Sigma), sodium selenite $\left(3 \times 10^{-8} \mathrm{M}\right.$; Sigma $)$, putrescine $\left(10^{-4} \mathrm{M}\right.$; Sigma $)$, conalbumin $(0.1$ $\mathrm{mg} / \mathrm{ml}$; Sigma), insulin $(5 \mu \mathrm{g} / \mathrm{ml}$; Sigma $)$, and penicillin-streptomycin (Life Technologies) was used. Cultures were incubated in a $5 \% \mathrm{CO}_{2}$ incubator at $37^{\circ} \mathrm{C}$ with saturated humidity. Treatment with $\mathrm{HGF}$ or muscle extract was accomplished by adding the appropriate concentration to the cells $2 \mathrm{hr}$ after initial plating. The data presented represent the summed results from three to four independent replications. Initially, MNs were identified by immunostaining using either SC- 1 or Islet-1/2 antibodies as specific MN markers (Milligan et al., 1994). On the basis of Islet immunolabeling 5-7 $\mathrm{hr}$ after plating, $78.5 \%$ of the cells were identified as MNs. After $2 \mathrm{~d}$ in culture, MN counts were made from 20 predetermined $20 \times$ fields in a phase-contrast microscope. To be included in the counts, an MN had to exhibit two or more neurites per soma that were twice the length of the soma diameter and contain no vacuoles or other signs of degeneration (e.g., beaded, disintegrating neurites). In this way, only apparent viable MNs were included in the counts. The number of surviving MNs at $48 \mathrm{hr}$ after treatment with optimal amounts (20 $\mu \mathrm{g} / \mathrm{ml}$ ) of chick embryo muscle extract (CMX), prepared as described (Oppenheim et al., 1988), was arbitrarily considered to be $100 \%$ survival.

In one experiment, cultures were treated with a nonsurvivalpromoting dose of CMX $(5 \mu \mathrm{g} / \mathrm{ml})$ together with an optimal dose $(1$ $\mathrm{ng} / \mathrm{ml}$ ) of HGF to assess for cooperative effects, and in a separate experiment both Islet-labeled and unlabeled cells were counted $48 \mathrm{hr}$ after treatment with $1 \mathrm{ng} / \mathrm{ml} \mathrm{HGF/SF}$.

Antibody blocking experiments. A blocking antibody to HGF/SF (antihuman HGF/SF monoclonal antibody 294) was purchased from R\&D Systems and shown to block the activity of recombinant chicken HGF/SF (rcHGF) (see Results). rcHGF was prepared as described by Théry et al., (1995) and generously provided by Claudio Stern (Columbia University, New York). The blocking antibody was incubated together with recombinant human HGF/SF (rhHGF), rcHGF/SF, or CMX for $1 \mathrm{hr}$ before the addition of MNs to the culture wells (see Table 1). For in vivo treatment with the HGF antibody, $15 \mu \mathrm{g}$ in $100 \mu \mathrm{l} \mathrm{BSA}$ was injected onto the chorioallantoic membrane through a window in the shell on E5 (stage 26) or on E7 (stage 31). Embryos were killed on either E6 (stage 29) or E8 (stage 34), and the brachial or lumbar spinal cord was processed for paraffin sectioning as described below. Surviving and degenerating (pyknotic) MNs were counted in every 10th section as described in Clarke and Oppenheim (1995). Controls were injected with $100 \mu \mathrm{l}$ of BSA.

In ovo treatment with trophic agents. Optimal doses of trophic agents $(5-10 \mu \mathrm{g})$ or CMX $(150 \mu \mathrm{g})$ were administered daily (E6-E9 or E6E11) onto the vascularized chorioallantoic membrane through a window in the shell as previously described (Oppenheim et al., 1988, 1993). Embryos were killed on E10 or E12, fixed in Carnoys solution, processed, serial-sectioned $(10 \mu \mathrm{m})$, and stained with thionin. To examine the effect of HGF/SF on cranial MNs, embryos were treated with $5 \mu \mathrm{g}$ daily from E9 to E13, and the following nuclei were examined on E14: oculomotor (III), trochlear (IV), trigeminal (V), abducens (VI), facial (VII), glossopharyngeal/vagus (IX-X), and hypoglossal (XII). A reliable and accurate cell counting procedure was used to assess healthy and pyknotic $\mathrm{MN}$ numbers in brachial, thoracic, and lumbosacral regions of the spinal cord and in the brainstem (Clarke and Oppenheim, 1995). Brachial and lumbosacral regions were identified by the beginning and end of the lateral motor column (LMC), and the thoracic was identified as the region between brachial and lumbosacral segments. Sensory neurons in the dorsal root ganglia (DRG) were counted on E10 in the third lumbar ganglion (L3). The trophic agents used here were kindly provided by Amgen (Thousand Oaks, CA) (BDNF, CNTF) and Genentech (South San Francisco, CA) (GDNF, HGF). In a separate in vivo experiment, HGF/SF $(5 \mu \mathrm{g})$ was administered on E4 and E5, and embryos were killed on E6.5 to examine the possible effects of HGF/SF on brachial and lumbar MNs before the main period of cell death.

$R T-P C R$. Total RNA was purified from E5, E6, E7, E8, E10, and E14 chick embryos, staged according to Hamburger and Hamilton (1951), that were removed from the shell and dissected in PBS $(138 \mathrm{~mm} \mathrm{NaCl}$, $2.7 \mathrm{~mm} \mathrm{KCl}, \mathrm{pH}$ 7.4) containing $2 \mathrm{~mm}$ EGTA. Skin and bones were removed from the forelimbs and hindlimbs, and the muscles were dissected and placed in Ultraspec RNA solution (Biotecx Laboratories, Houston TX) on ice. Total RNA was then purified from the limb muscles using the Ultraspec RNA isolation system according to the manufacturer's instructions. To ascertain that all RNA samples would be DNA-free, samples were treated with RQ1 DNase I (Promega, Madison WI) for 1 $\mathrm{hr}$ at $37^{\circ} \mathrm{C}$. The purified RNA was measured and checked on a formaldehyde gel (Ausubel et al., 1996) to confirm that it was not degraded and that quantifications were accurate. 
Measurements of GAPDH and HGF/SF gene expression were made using the Access RT-PCR System (Promega) according to manufacturer's instructions. The $50 \mu \mathrm{l}$ reactions included $1 \mu \mathrm{g}$ of total RNA, Promega AMV/Tf1 reaction buffer, $0.2 \mathrm{mM}$ dNTP mix, $5 \mathrm{U}$ AMV reverse transcriptase, $5 \mathrm{U}$ Tfl DNA polymerase, 50 pmol each of forward and reverse primers, and $1 \mathrm{~mm} \mathrm{MgSO}_{4}$. The GAPDH forward primer encompassed nucleotides (nt) 77-99 of the chicken GAPDH gene (GenBank accession no. K01458), and the reverse primer encompassed nt 502-523. The HGF/SF forward primer encompassed nt 905-927 of the chick HGF/SF gene (GenBank accession no. X84045), and the reverse primer encompassed nt 1352-1332. cDNAs were first created from each RNA sample by allowing the reverse transcription reaction to occur at $48^{\circ} \mathrm{C}$ for $45 \mathrm{~min}$, followed by a $2 \mathrm{~min}$ incubation at $94^{\circ} \mathrm{C}$. The polymerase chain reaction then took place using the following thermal cycler programs: 35 cycles of $94^{\circ} \mathrm{C}$ for $30 \mathrm{sec}, 60^{\circ} \mathrm{C}$ for $1 \mathrm{~min}$, and $68^{\circ} \mathrm{C}$ for $2 \mathrm{~min}$ for GAPDH primers, and 40 cycles of $94^{\circ} \mathrm{C}$ for $30 \mathrm{sec}, 56^{\circ} \mathrm{C}$ for $1 \mathrm{~min}$, and $68^{\circ} \mathrm{C}$ for $2 \mathrm{~min}$ for $\mathrm{HGF} / \mathrm{SF}$ primers. PCR products were analyzed on $3 \%$ agarose gels. Negative controls included PCR reactions lacking primers or reverse transcriptase. The RT-PCR results shown were repeated in four separate experiments.

In situ hybridization. Plasmids containing portions of the chick c-met gene (c-met/pcDNA) and chick HGF/SF gene (pollo 199F) were generously provided by Claudio Stern. Digestion of c-met/pcDNA with PstI and Bam HI yielded a $1.8 \mathrm{~kb}$ fragment encompassing nt 1695-3573. This fragment was ligated to Pst $\mathrm{I} /$ Bam HI-digested pBluescript $\mathrm{KS}^{-}$(Stratagene, La Jolla, CA) to create the plasmid c-met/BS. The plasmid pollo $199 \mathrm{~F}$ contains $1.2 \mathrm{~kb}$ of $5^{\prime} \mathrm{HGF} / \mathrm{SF}$ coding sequence in the pBluescript $\mathrm{KS}^{-}$vector. Digoxygenin (DIG)-labeled riboprobes were prepared from linearized c-met/BS and pollo 199F plasmids according to manufacturer's instructions (Boehringer Mannheim, Indianapolis, IN), followed by RQ1 DNase I (Promega) digestion. Riboprobe size was confirmed on formaldehyde gels (Ausubel et al., 1996), and optimal probe concentration was determined by serial dilution. DIG-labeled c-met sense riboprobes were used as negative controls.

Spinal cords were dissected from E4, E5, E6, E7, E8, E10, and E12 chick embryos and brains from E13 embryos into PBS containing $2 \mathrm{~mm}$ EGTA [staged according to Hamburger and Hamilton (1951)] and immediately placed in PBS, $\mathrm{pH} 7.4$, containing $4 \%$ paraformaldehyde. Spinal cords were then cryoprotected sequentially in 5\% sucrose/PBS, $15 \%$ sucrose/PBS, and $20 \%$ sucrose/PBS for $4 \mathrm{hr}$ each at $4^{\circ} \mathrm{C}$. They were then embedded in O.C.T. (Tissue Tek), and frozen on dry ice. Serial sections $(20 \mu \mathrm{m})$ were cut at $-20^{\circ} \mathrm{C}$ and stored at $-80^{\circ} \mathrm{C}$. In situ hybridization was performed according to Yamamoto et al. (1997). The E4, E5, E6, E7, E8, E10, and E12 sections from brachial, thoracic, and lumbar regions and E13 brain were all included in each of three independent experiments, and sections of each time point and spinal cord region were all hybridized with sense and antisense c-met probes.

Immunohistochemistry. Islet-1/2 immunohistochemistry was performed on spinal cords of chick embryos dissected in PBS, fixed, cryoprotected, embedded, and sectioned as described above. Sections were rehydrated in PBS at room temperature two times for 5 min each. Endogenous peroxidase activity was quenched in $3 \% \mathrm{H}_{2} \mathrm{O}_{2}, 10 \% \mathrm{MeOH}$, $10 \mathrm{~mm}$ Tris, $\mathrm{pH}$ 7.5, two times for $15 \mathrm{~min}$ each. Sections were washed once for $10 \mathrm{~min}$ in PBS and blocked in complete buffer (10\% normal goat serum, $0.1 \%$ Triton-X 100 in PBS) for $1 \mathrm{hr}$ at room temperature. The Islet-1/2 reactive antibody 4D5 (Developmental Studies Hybridoma Bank, Iowa City, IA) was diluted 1:250 in complete buffer, applied to sections, and allowed to incubate overnight at $4^{\circ} \mathrm{C}$. Sections were then treated with the secondary antibody, biotinylated goat anti-mouse IgG (Vector Laboratories, Burlingame, CA), at a 1:100 dilution in complete buffer for $1 \mathrm{hr}$ at $4^{\circ} \mathrm{C}$. Sections were washed three times for 5 min each in PBS at room temperature, and antibody reactivity was observed using the Vectastain ABC and DAB kits (Vector), an avidin DH, and biotinylated horseradish peroxidase detection system.

Limb bud removal. Limb bud removal (LBR) experiments were performed on E3 as previously described (Caldero et al., 1998). After LBR, some embryos were allowed to survive until E5.0 (stage 25), when the lumbar region of the spinal cord was dissected, fixed, cryoprotected, and sectioned as described above. In situ hybridization of the c-met antisense riboprobe was performed as described above, and results shown were repeated in at least five separate in situ hybridization experiments, performed on spinal cord sections from three different embryos. Other LBR embryos were treated with HGF $(5 \mu \mathrm{g})$ alone, a nonoptimal dose of MEX $(15 \mu \mathrm{g})$ alone, or HGF $(5 \mu \mathrm{g})$ plus a nonoptimal dose $(15 \mu \mathrm{g})$ of
CMX on E4, E5, E6, and E7 and killed on E7.5. The spinal cord was processed and sectioned, and MNs were counted as described above.

\section{RESULTS HGF/SF supports the in vitro survival of lumbar MNs}

To investigate the role of $\mathrm{HGF} / \mathrm{SF}$ in promoting survival of specific MN subpopulations, we first tested the ability of HGF/SF to support survival of different MN populations in vitro. Motoneurons were purified from the ventral region of brachial, thoracic, and lumbar chick spinal cord at E5.0. In the absence of muscle extract (CMX) or trophic factors, virtually all chick MNs in vitro die within 48-72 hr. Recombinant human HGF/SF was added to cultured MNs, and the number of surviving cells was compared with control cultures. After $48 \mathrm{hr}$ of treatment with different concentrations of $\mathrm{HGF} / \mathrm{SF}$, we observed a dosedependent increase in the survival of lumbar-derived MNs (Fig. $1 A$ ). By contrast, HGF, even at doses as high as $100 \mathrm{ng} / \mathrm{ml}$ (data not shown), failed to promote the survival of brachial or thoracic MNs (Fig. 1B). Treatment with CMX, however, promoted the survival of all three populations (brachial, thoracic, and lumbar) of MNs (data not shown). Thus, HGF/SF appears to promote the survival of lumbar but not brachial or thoracic MNs in vitro. To examine whether HGF/SF might be acting indirectly on MNs in vitro via a survival effect on the other cells (non-MNs), some cultures were immunolabeled with Islet-1/2, and the number of unlabeled cells was counted. After $48 \mathrm{hr}$ exposure to $\mathrm{HGF} / \mathrm{SF}$, the number of unlabeled cells was unchanged (control $=220 \pm 25$ vs HGF $=200 \pm 35$ ). Therefore, we conclude that changes in the number of non-MNs after HGF treatment are not responsible for increased MN survival. In comparing the effects of HGF/SF with previous studies of BDNF (Becker et al., 1998), GDNF, and CNTF (Oppenheim et al., 1995), HGF/SF appears to be more potent than CNTF or GDNF but is equally as potent as BDNF (Fig. $1 B$ ). That is, lower optimal doses of HGF and BDNF were required for maximum survival compared with GDNF and CNTF. However, HGF was less efficacious (i.e., rescued fewer MNs at optimal doses) than either BDNF or GDNF. Cotreatment with HGF (1 ng/ml) and a suboptimal dose of CMX (5 $\mu \mathrm{g} / \mathrm{ml})$, which by itself has no survival-promoting effect, increased the survival effects of HGF from 60 to $75 \%$ (Fig. 1C). Recombinant chicken $\mathrm{HGF} / \mathrm{SF}$ also promoted the survival of lumbar MNs in vitro (Fig. $1 D$ ), although higher doses were required, probably because of the fact that the chicken protein had been stored frozen $\left(-80^{\circ} \mathrm{C}\right)$ for several years and had lost activity (C. Stern, personal communication).

\section{Antibody blocking experiments}

Anti-HGF (10-30 $\mu \mathrm{g} / \mathrm{ml})$ blocked the in vitro MN survivalpromoting effects of $100 \mathrm{ng} / \mathrm{ml}$ recombinant human $\mathrm{HGF} / \mathrm{SF}$ and of recombinant chicken $\mathrm{HGF} / \mathrm{SF}$ and significantly reduced the survival-promoting effects of CMX (Table 1). After in vivo treatment with anti-HGF on E5, MN numbers in both brachial and lumbar spinal cord on E6 were similar to control values (Table 2). By contrast, anti-HGF treatment on E7 resulted in a significant decrease in the number of lumbar MNs on E8 but no change in brachial MNs (Table 2). The relatively small absolute reduction in lumbar MNs was to be expected, considering the short duration of treatment $(30 \mathrm{hr})$ and the fact that $\mathrm{HGF} / \mathrm{SF}$ is probably acting on only a subpopulation of lumbar MNs. Treatment with antiHGF was without effect on the number of degenerating MNs on E6 but increased the number of pyknotic lumbar MNs on E8 (Table 2). The lack of effect of anti-HGF in the brachial region 

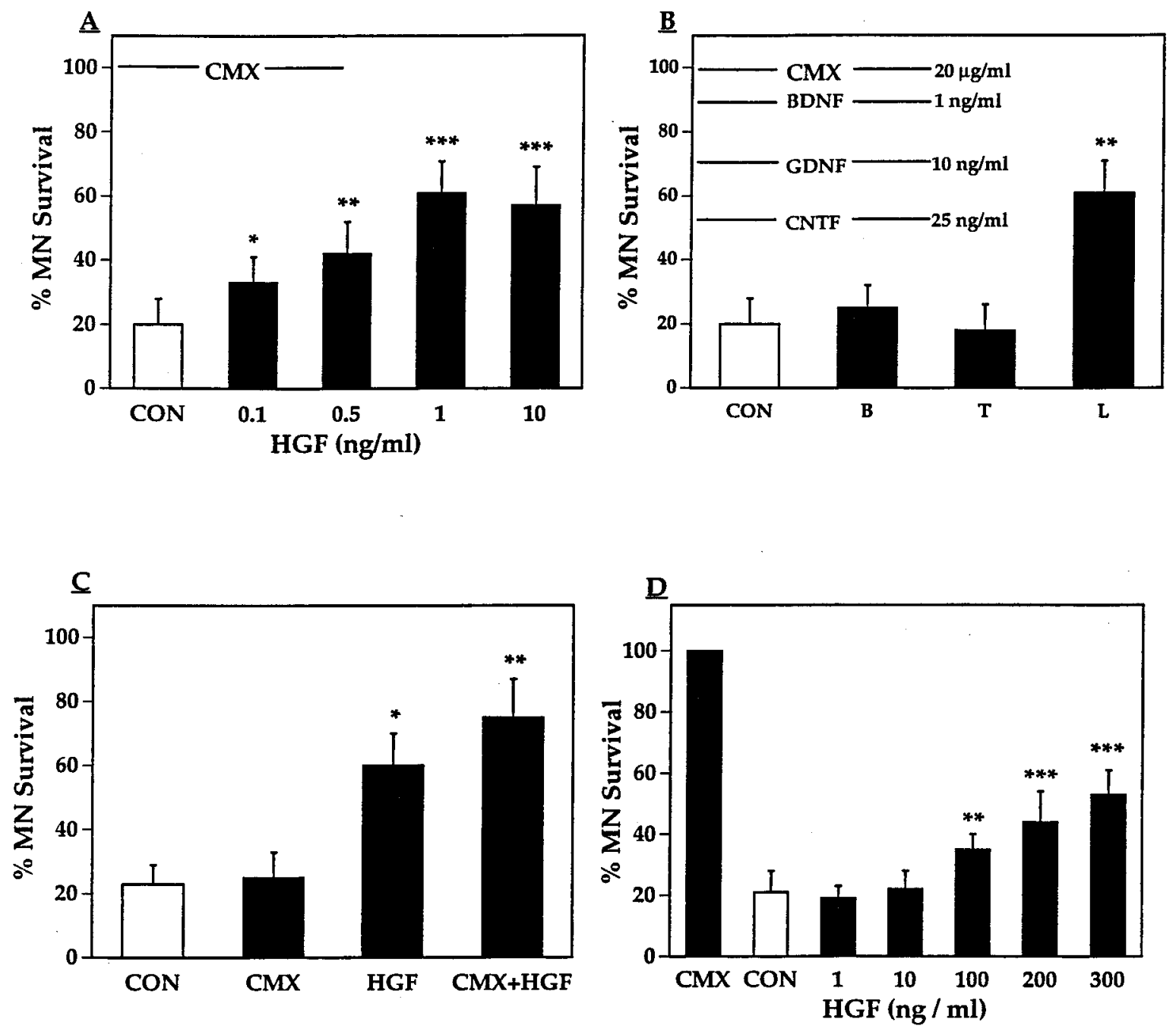

Figure 1. The percentage survival (mean $\pm \mathrm{SD}$ ) of cultured MNs at $48 \mathrm{hr}$ relative to CMX (A, horizontal line) after treatment of lumbar-derived cultures $(A)$ or $(B)$ after treatment of lumbar $(L)$-, brachial $(B)$-, or thoracic $(T)$-derived MNs with HGF/SF. In $B$ the data for L-, B-, and T-derived MNs $($ bars $)$ represent treatment with a dose of $10 \mathrm{ng} / \mathrm{ml}$ of HGF/SF. Data for CMX, BDNF, GDNF, and CNTF ( $B$, horizontal lines) represent percentage survival of lumbar MNs using optimal doses of each factor. The data for BDNF are extrapolated from Becker et al. $(1998)$. ${ }^{*} p<0.05$; ** $p<0.01(A)$ or $p<$ $0.001(B) ;{ }^{* * *} p<0.001$. ( $t$ tests vs control, $\left.C O N\right)$. $C$, MN survival after treatment with CMX $(5 \mu \mathrm{g} / \mathrm{ml})$, HGF $(5 \mathrm{ng} / \mathrm{ml})$, or HGF $+\mathrm{CMX}$. ${ }^{*} p<0.01 \mathrm{versus}$ $\mathrm{CON} ;{ }^{* *} p<0.05$ versus HGF. $D$, MN survival after treatment with $\mathrm{rcHGF}$. ${ }^{*} p<0.001$ versus CMX; $* * p<0.05$ versus CON; *** $p<0.01$ versus CON.

provides a negative control against the possible nonspecific effects of anti-HGF in reducing MNs in the lumbar spinal cord.

\section{HGF/SF promotes spinal MN survival in ovo}

Although HGF/SF has been shown to be a survival factor for mammalian and avian MNs in vitro (Ebens et al., 1996; Wong et al., 1997; Yamamoto et al., 1997; present results), its in vivo role in $\mathrm{MN}$ survival has not yet been examined. The ability to add drugs, chemicals, and growth factors to the developing chick embryo in ovo makes this system ideal for such experiments. Accordingly, HGF/SF was administered in vivo via the highly vascularized chorioallantoic membrane that surrounds the embryo and is connected to the embryonic circulatory system. Agents administered in this way have access to both peripheral and central neurons, and this method has proven to be an efficient and effective means for the systemic administration of various agents, including neurotrophic factors (Oppenheim et al., 1988, 1993). Embryos were treated daily with an optimal dose of $\mathrm{HGF} / \mathrm{SF}(5 \mu \mathrm{g})$, whereas control embryos received equal volumes of a physiological saline solution. At E10 or E12, the embryos were killed, and the number of surviving MNs in the brachial, lumbar, and thoracic spinal cord was counted (Clarke and Oppenheim, 1995). We observed that $\mathrm{HGF} / \mathrm{SF}$ promoted the survival of a significant number of MNs in the lumbar LMC compared with saline-treated controls but had no affect on MNs in the brachial or thoracic region of the spinal cord (Fig. 2A). $\mathrm{HGF} / \mathrm{SF}$ and BDNF were less efficacious than CNTF, GDNF, or $\mathrm{CMX}$ in promoting lumbar MN survival in ovo (Fig. 2C). $\mathrm{HGF} / \mathrm{SF}$ reduced the number (mean $\pm \mathrm{SD}$ ) of pyknoticdegenerating lumbar MNs per 1000 surviving MNs on E8.0 $(\mathrm{HGF} / \mathrm{SF}=12.5 \pm 1.5, n=5 \mathrm{vs}$ control $=18.7 \pm 3.1, n=5 ; p<$ $0.05, t$ test).

Because MNs in the brachial region of the spinal cord begin PCD 1-2 d later than lumbar MNs (E7-E8 vs E6) and cell loss continues to about E13 (Oppenheim and Majors-Willard, 1978), treatment with $\mathrm{HGF} / \mathrm{SF}$ was also extended to the later cell death period. HGF/SF was administered in ovo from E6 to E12, and the number of MNs in brachial, lumbar, and thoracic regions of the spinal cord was counted on E12.5. Despite the more prolonged 


\begin{tabular}{llllll}
\hline \multicolumn{3}{l}{ Table 1. In vitro } & anti-HGF experiment \\
CMX & CON & rhHGF & rcHGF & rhHGF + anti-HGF & rcHGF + anti-HGF \\
\hline 100 & $23^{a}$ & $63^{b}$ & $42^{c}$ & $20^{d}$ & $27^{d}$ \\
$( \pm 13)$ & $( \pm 8)$ & $( \pm 11)$ & $( \pm 7)$ & $( \pm 7)$ & $( \pm 6)$ \\
\hline
\end{tabular}

Cultured MNs were treated with CMX (20 $\mu \mathrm{g} / \mathrm{ml})$, rhHGF (100 ng/ml), rcHGF (100 ng/ml), and anti-HGF (10-30 $\mu \mathrm{g} / \mathrm{ml}$; see Materials and Methods). The values represent mean $( \pm \mathrm{SD}) \%$ survival at $48 \mathrm{hrs}$ as explained in Materials and Methods.

${ }^{a} p<0.01$ vs CMX.

${ }^{b} p<0.01$ vs CON.

${ }^{c} p<0.05$ vs CON.

${ }^{d} p<0.01$ vs rhHGF or vs rhHGF.

${ }^{e} p<0.05$ vs CMX (Student $t$ tests).

treatment period, $\mathrm{HGF} / \mathrm{SF}$ still did not promote survival of either brachial or thoracic MNs but did significantly increase MN number in the lumbar region (Fig. $2 B$ ). Thus, HGF/SF has a specific effect of only promoting survival of MNs from the lumbar region of the spinal cord during the period of their naturally occurring cell death. Treatment with HGF/SF from E6 to E10 or E12 also had no effect on cell size (nuclear area) of lumbar MNs (control $=150 \pm 25 \mu \mathrm{m}^{2} v s \mathrm{HGF}=147 \pm 12 \mu \mathrm{m}^{2} ; n=200$ cells per group). Finally, treatment with $\mathrm{HGF} / \mathrm{SF}(5 \mu \mathrm{g})$ on E4 and E5, before the main cell death period of brachial and lumbar MNs, was without effect on the number of surviving MNs on E6.5 (brachial control $=15,100 \pm 861, n=4$ vs brachial HGF/SF $=$ $15,416 \pm 610, n=4$; lumbar control $=20,293 \pm 1,019, n=4$ vs lumbar HGF/SF $=19,875 \pm 862, n=4)$.

Motoneurons were also counted in different rostral-caudal regions of the lumbar spinal cord to determine whether subsets of lumbar MNs have a differential survival response to $\mathrm{HGF} / \mathrm{SF}$. When MN numbers were counted in 10 different equal regions along the rostral-caudal axis of the lumbar spinal cord on E10 and E12, we observed an increase in the number of MN cell bodies in the caudalmost two-thirds of the lumbar region, whereas the rostralmost third of the lumbar region did not have an increased number of MNs above that of the saline-treated controls (data not shown). Finally, daily HGF/SF treatment (5 $\mu \mathrm{g})$ from E6 to E12 failed to promote the survival of lumbar sensory neurons in the L3 DRG $(10,570 \pm 1,129, n=5$ vs control $=11,141 \pm 1,090, n=5)$.

\section{HGF/SF does not promote cranial motor neuron survival in ovo}

We also tested the effects of $\mathrm{HGF} / \mathrm{SF}$ on cranial MN survival. In the chick embryo, cranial MN cell death occurs from E9 to E15 (Oppenheim et al., 1993; Johnson et al., 1995). To test the in vivo effects of $\mathrm{HGF} / \mathrm{SF}$ on cranial MN survival, $5 \mu \mathrm{g} \mathrm{HGF/SF}$ was added to embryos in ovo from E9 to E13. Embryos were killed on E14, and MNs were counted in the nuclei of cranial nerves III (oculomotor), IV (trochlear), V (trigeminal), VI (abducens), V II (facial), IX (glossopharyngeal), X (vagus), and XII (hypoglossal). No differences were observed in the number of surviving MNs for any of the cranial motor nuclei as compared with saline-treated controls (Fig. 3). This was surprising, because c-met expression was observed at several ages between E9 and E14 in cranial motor nuclei III, IV, V, VII, IX, and X (data not shown). Additionally, although not shown here, c-met staining was also observed in the ventral lateral geniculate nucleus, the nucleus dorsolateralis anterior thalami, the nucleus rotundus, and the optic tectum (layer 4 and layers 8-10 of the stratum griseum at fibrosum superficiale), all of which are visual relay nuclei (Nieuwenhuys et al., 1998). The significance of this expression is unknown.

\section{The HGF/SF receptor c-met is expressed in MN subsets during PCD}

Because only a subset of MNs were capable of responding to $\mathrm{HGF} / \mathrm{SF}$, we sought to determine the expression pattern of the receptor tyrosine kinase c-met, the receptor for $\mathrm{HGF} / \mathrm{SF}$ (Botarro et al., 1991; Naldini et al., 1991). Previous studies have shown that c-met is expressed in the ventral horn of mouse embryo spinal cord (Sonnenberg et al., 1993), and detailed studies in rat embryos have revealed that c-met is expressed only in MNs in limb-innervating segments (Yamamoto et al., 1997). We performed in situ hybridization with the c-met antisense riboprobes on brachial, thoracic, and lumbar spinal cord sections at ages throughout the period of PCD. Immunohistochemistry with an antibody against the Islet-1/2, LIM-family transcription factors expressed by developing MNs (Tsuchida et al., 1994), was used to

Table 2. In vivo anti-HGF experiment

\begin{tabular}{|c|c|c|c|c|c|c|c|c|}
\hline & \multicolumn{4}{|l|}{ Control } & \multicolumn{4}{|c|}{ Anti-HGF } \\
\hline & \multicolumn{2}{|l|}{ Brachial } & \multicolumn{2}{|l|}{ Lumbar } & \multicolumn{2}{|c|}{ Brachial } & \multicolumn{2}{|c|}{ Lumbar } \\
\hline & E6 & E8 & E6 & E8 & E6 & E8 & E6 & E8 \\
\hline Healthy & $\begin{array}{l}15,500 \\
\pm 1,165 \\
(5)\end{array}$ & $\begin{array}{l}13,109 \\
\pm 852 \\
(5)\end{array}$ & $\begin{array}{l}21,506 \\
\pm 1,261 \\
(5)\end{array}$ & $\begin{array}{l}18,172 \\
\pm 841 \\
(5)\end{array}$ & $\begin{array}{l}16,207 \\
\pm 987 \\
(5)\end{array}$ & $\begin{array}{l}13,566 \\
\pm 950 \\
(5)\end{array}$ & $\begin{array}{l}20,665 \\
\pm 1,133 \\
(5)\end{array}$ & $\begin{array}{l}16,823^{*} \\
\pm 770 \\
(5)\end{array}$ \\
\hline Pyknotic & $\begin{array}{l}0.8 \\
\pm 0.2 \\
(5)\end{array}$ & $\begin{array}{l}18.3 \\
\pm 5 \\
(6)\end{array}$ & $\begin{array}{l}2.8 \\
\pm 0.7 \\
(5)\end{array}$ & $\begin{array}{l}21 \\
\pm 3 \\
(6)\end{array}$ & $\begin{array}{l}1.0 \\
\pm 0.3 \\
(5)\end{array}$ & $\begin{array}{l}17.7 \\
\pm 4 \\
(5)\end{array}$ & $\begin{array}{l}2.3 \\
\pm 0.6 \\
(5)\end{array}$ & $\begin{array}{l}29^{*} \\
\pm 3 \\
(8)\end{array}$ \\
\hline
\end{tabular}

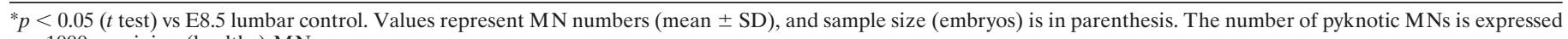
per 1000 surviving (healthy) MNs. 

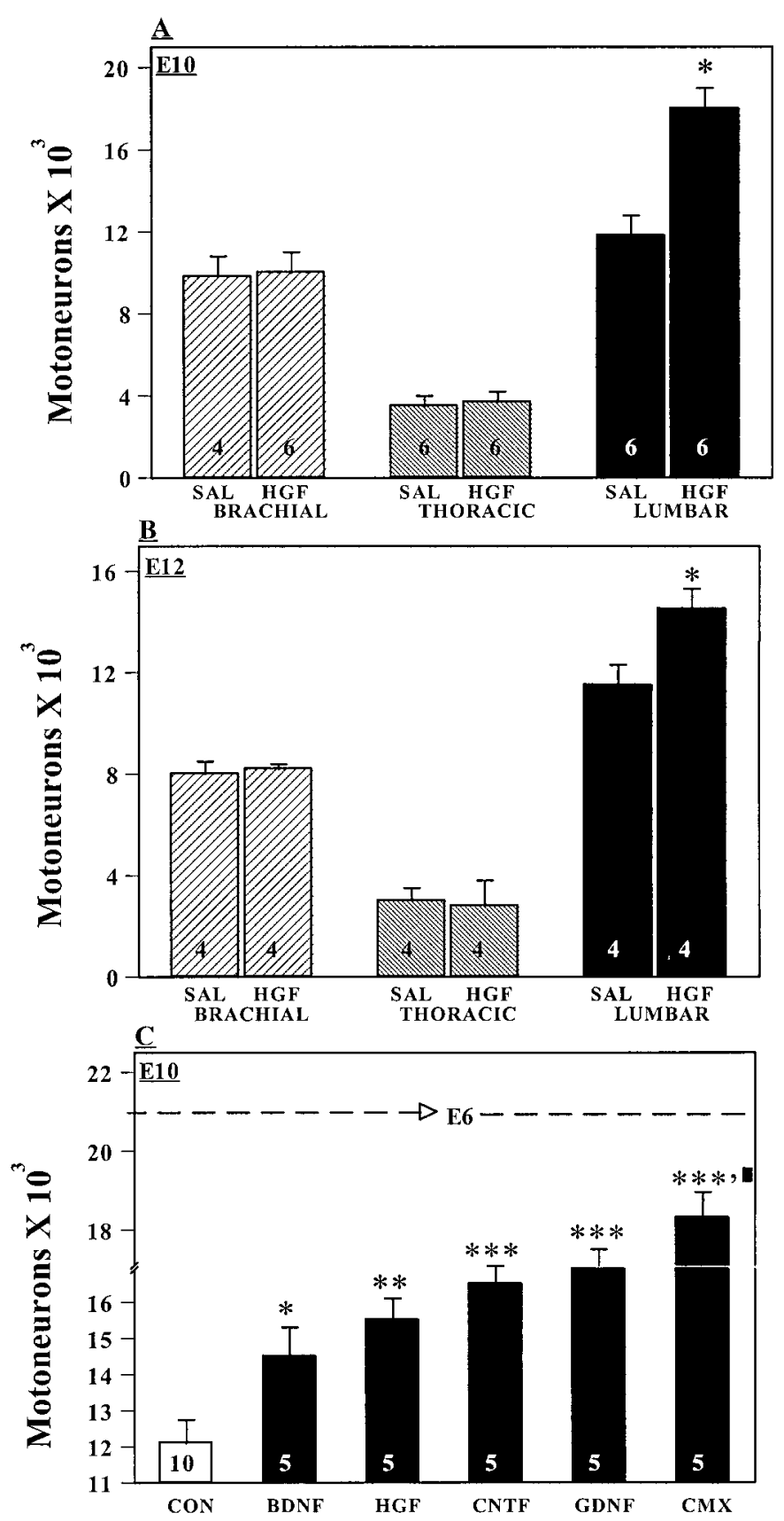

Figure 2. $A, B$, The number (mean $\pm \mathrm{SD}$ ) of MNs on E10 $(A)$ and $\mathrm{E} 12$ $(B)$ after daily in ovo treatment with $5-10 \mu \mathrm{g}$ of HGF/SF from E6. Values in bars $=$ number of animals. ${ }^{*} p<0.005$. $C$, The number (mean $\pm \mathrm{SD}$ ) of lumbar MNs on E10 after daily in ovo treatment from E6 with saline (CON), BDNF $(5 \mu \mathrm{g}), H G F(5 \mu \mathrm{g}), C N T F(5 \mu \mathrm{g}), G D N F(5 \mu \mathrm{g})$, or $C M X$ $(150 \mu \mathrm{g}) .{ }^{*} p<0.01 ;{ }^{*} p<0.005$; *** $p<0.001$; vs CON; $p<0.01$ vs GDNF ( $t$ tests). At comparable doses $(5 \mu \mathrm{g}) \mathrm{CNTF}$ and GDNF rescued more MNs than BDNF or HGF (CNTF and GDNF vs BDNF, $p<0.02$; $\mathrm{CNTF}$ and GDNF vs HGF, $p=0.05)$. The horizontal line represents the number of MNs present on E6 $(21,000)$.

clearly distinguish the LMC where the MN cell bodies reside (Fig. $4 F)$.

The HGF/SF receptor c-met was observed to be expressed in the lumbar LMC of E5 embryos (Fig. 4B) but not on E4 (Fig. $4 A$ ), which was the youngest age examined, and expression appeared to increase as development progressed, with clearly de-

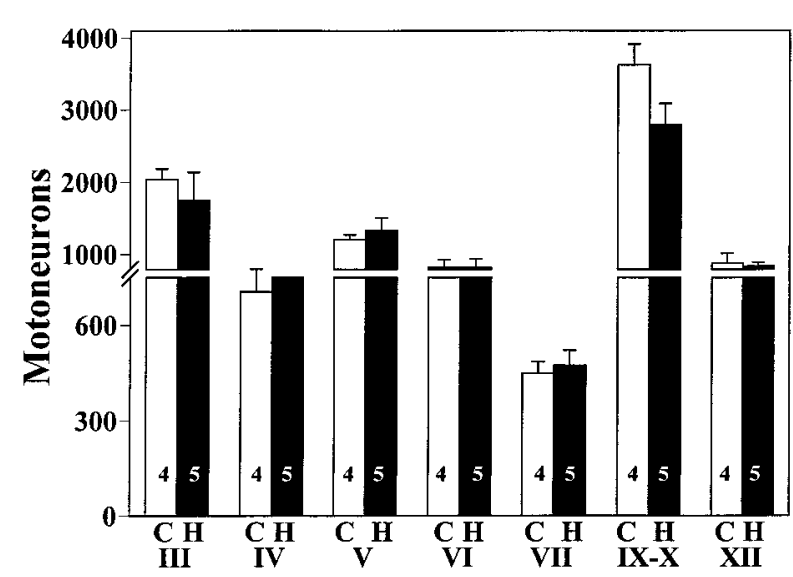

Figure 3. The number (mean $\pm \mathrm{SD}$ ) of cranial MNs on E14 after daily HGF treatment $(5 \mu \mathrm{g})$ from E9 to E13. $C$, Control; $H$, HGF.

tectable levels of c-met expression in E6, E7, and E8 lumbar spinal cord (Fig. 4C-G). Although c-met was expressed throughout the LMC, it appeared to be more highly expressed in distinct areas of the LMC, which may correspond to subsets of lumbar MNs (Fig. 4J-L). However, there was no apparent difference in c-met expression in lumbar MNs at different locations along the rostral-caudal axis. Expression levels appeared to decrease toward the end of PCD, because c-met expression was lower in the ventral horn by E10 (Fig. 4H) and could no longer be detected in E12 lumbar spinal cord (Fig. 4I). The c-met sense riboprobe (negative control) did not cross-react with any specific regions of the spinal cord (Fig. 4E). High magnification photomicrographs of c-met and Islet-1/2 expression in the lumbar LMC on E7 are shown in Figure $4 J-L$.

$\mathrm{C}$-met staining was not observed in thoracic spinal cord sections at E7 (Fig. 4N) or on E4, E5, E6, E8, E10, or E12 (data not shown). Compared with lumbar spinal cord (Fig. 4O), only a small region of c-met expression was consistently observed in the lateralmost region of the LMC in the brachial region on E7 (Fig. $4 M)$, with little if any expression at the other ages examined, including E4-E6 and E8-E12 (data not shown). Weak expression was also observed to be diffusely distributed throughout the gray matter of the entire spinal cord (brachial, thoracic, lumbar) from E4 to E10, although it is not clear whether this staining is specific to neurons or glia.

\section{HGF/SF is expressed in the limbs during PCD}

$\mathrm{HGF} / \mathrm{SF}$ was observed to promote MN survival both in vitro and in vivo, and the $\mathrm{HGF} / \mathrm{SF}$ receptor c-met was expressed at the proper time and in the appropriate location to act as a trophic factor specific for lumbar MNs. Because lumbar MNs innervate the muscles of the lower limb, we asked whether HGF/SF is expressed in lower limb musculature during the same time period that c-met expression is observed. Using whole-mount in situ hybridization with $\mathrm{HGF} / \mathrm{SF}$ antisense riboprobes, we detected $\mathrm{HGF} / \mathrm{SF}$ in both upper and lower limb buds, in the heart, and in the brain, as previously observed (Thèry et al., 1995), as well as in branchial arches and apparent muscle precursor cells around the eye, of stage 17 (E2.5) embryos (data not shown). After E2.5, however, we were unable to consistently demonstrate $\mathrm{HGF} / \mathrm{SF}$ expression in the limbs either by whole mount or on sections using in situ hybridization.

Because of the failure of in situ hybridization to detect HGF/SF in the limbs after E2.5, we also assayed HGF/SF expression in the 

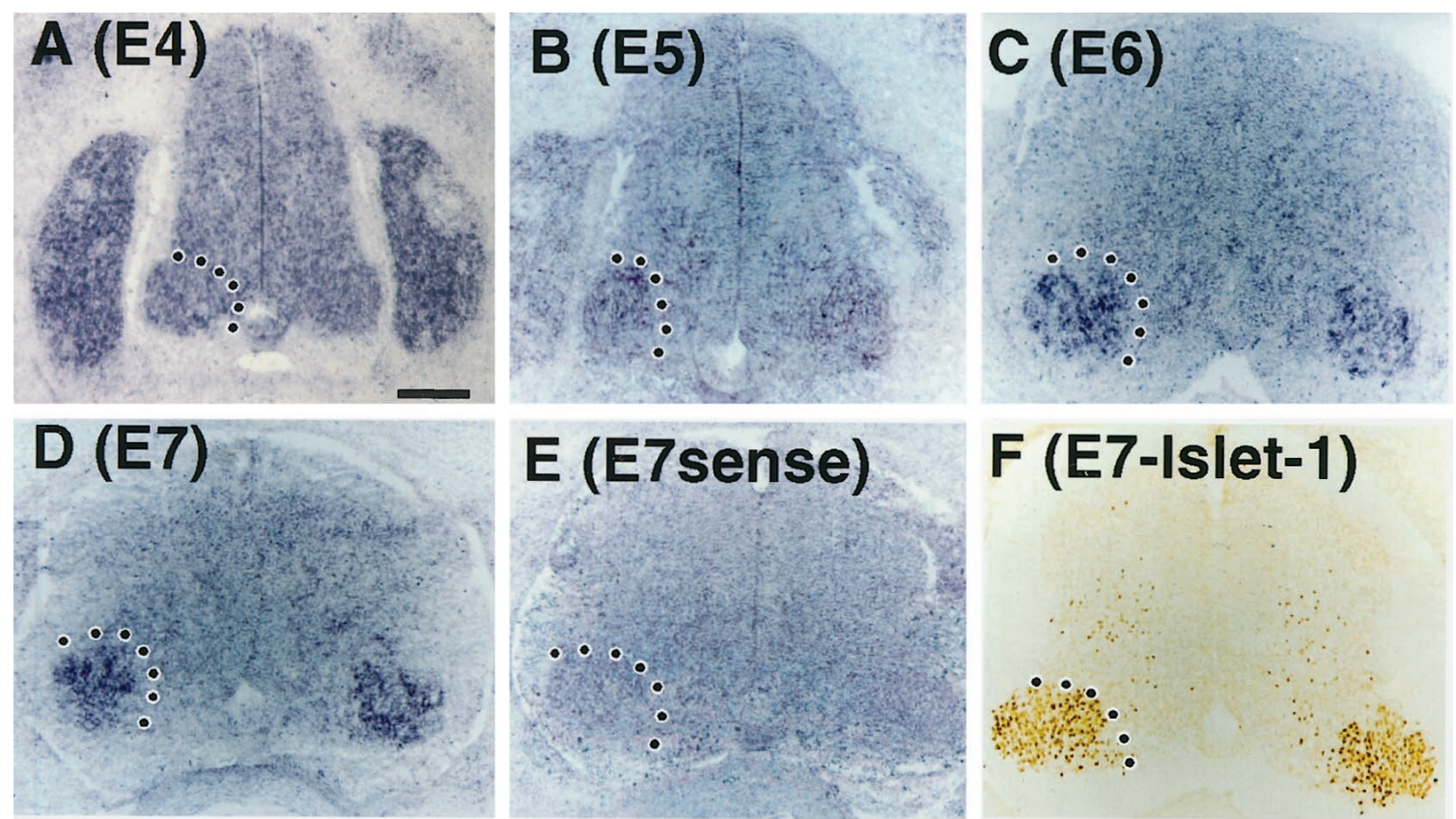

\section{E (E7sense)}

\section{F (E7-Islet-1)}
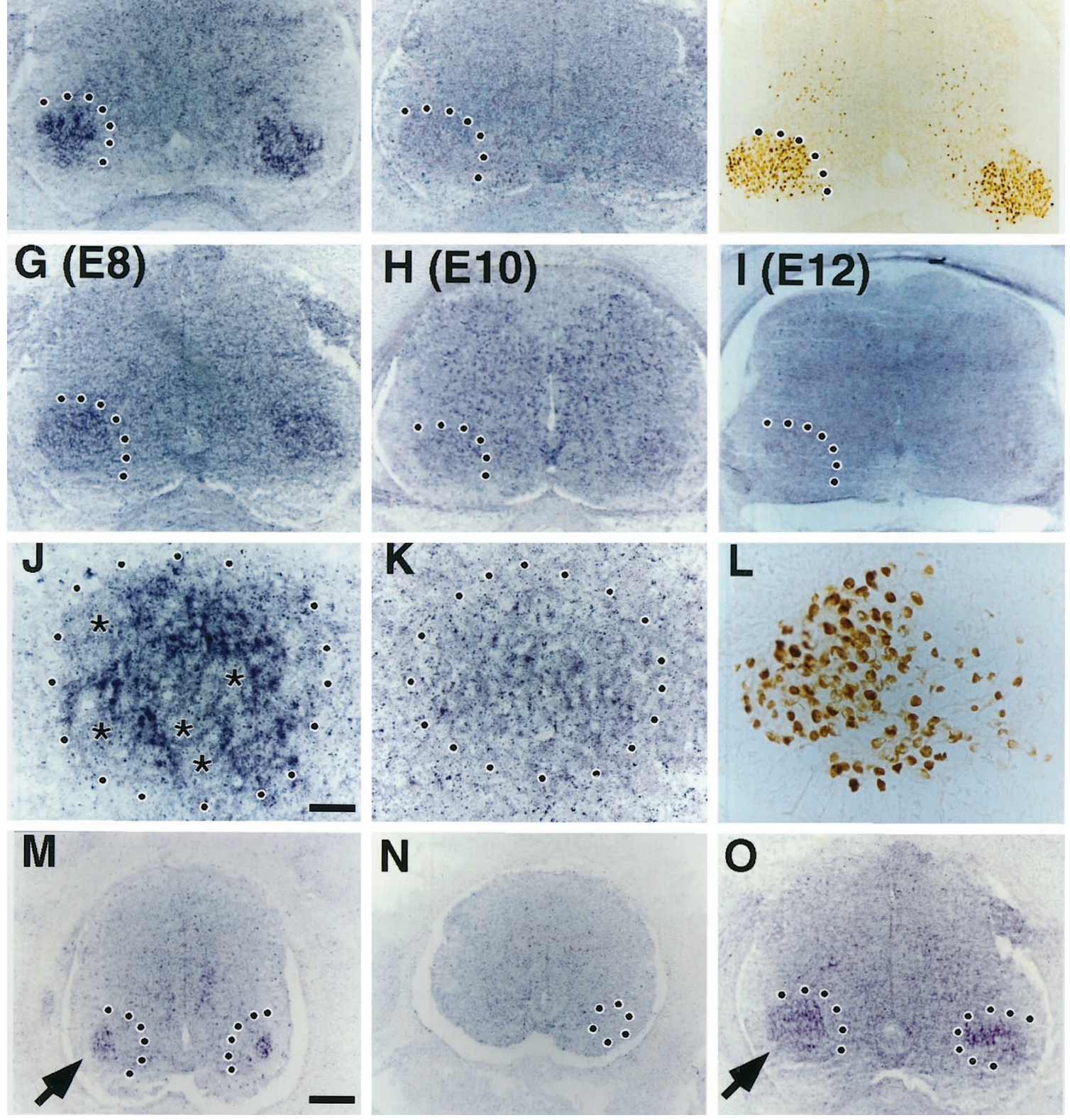

Figure 4. In situ hybridization was performed using the c-met antisense probe on sections of lumbar spinal cord at E4 $(A)$, E5 $(B)$, E6 $(C)$, E7 $(D)$, E8 $(G)$, E10 $(H)$, E12 $(I)$. A c-met sense probe was hybridized with E7 lumbar sections as a negative control $(E)$, and immunohistochemistry with the anti-Islet-1/2 antibody was used to clearly mark MNs in the lumbar LMC on E7 $(F)$. Dotted lines delineate the ventral horn. Scale bar in A $=200 \mu \mathrm{m}$ for $A-I$ and $100 \mu \mathrm{m}$ for $G-I$. $M-O$, Spinal cord sections from E7 brachial $(M)$ and thoracic $(N)$ regions were also examined for c-met expression by in situ hybridization with the c-met antisense probe, and compared to E7 lumbar sections $(O)$. Dotted lines and arrows delineate the ventral horn. $J-L$, High magnification photomicrographs of the mid-lumbar LMC on E7 after in situ hybridization was performed with an antisense c-met probe $(J)$, a c-met sense probe $(K)$, and after immunohistochemistry with the Islet-1/2 antibody $(L)$. Data shown are indicative of four independent experiments on at least three different embryos. Dotted lines in $J$ and $K$ delineate the LMC. The asterisks in $J$ indicate regions containing MNs but with little, if any, apparent c-met expression. Scale bar (shown in $J$ for $J-L$ ): $30 \mu \mathrm{m}$. 


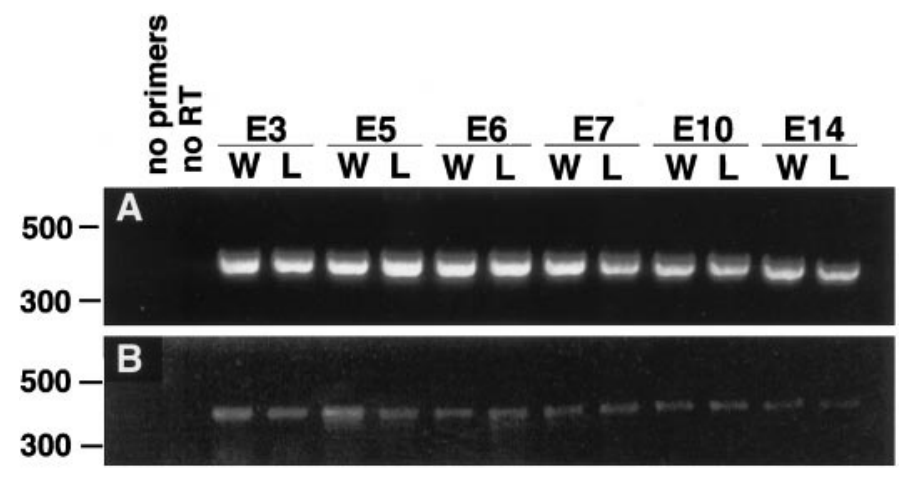

Figure 5. RT-PCR was used to assess HGF/SF expression $(B)$ in wing $(W)$ and leg muscle $(L)$ from E3, E5, E6, E7, E10, and E14 embryos. GAPDH primers were used as a positive control $(A)$. RT-PCR reactions with $\mathrm{HGF} / \mathrm{SF}$ primers yielded the predicted 448 bp product $(B)$. Negative controls included reactions with no primers or no reverse transcriptase. Results shown are representative of four independent experiments. DNA base pair markers are shown at left.

developing chick limb using RT-PCR, which is a more sensitive method than in situ hybridization for detecting low amounts of mRNA. Wings and legs were dissected from E3, E5, E6, E7, E10, and E14 embryos, and total RNA was purified after digestion of DNA. Equal amounts of RNA were used in RT-PCR reactions to quantify HGF/SF expression in upper and lower limbs during the period of naturally occurring cell death. RT-PCR with GAPDH primers yielded a $447 \mathrm{bp}$ product and confirmed that equal amounts of RNA were included in each reaction (Fig. 5A). RT$\mathrm{PCR}$ reactions with $\mathrm{HGF} / \mathrm{SF}$ primers yielded the predicted $448 \mathrm{bp}$ product, with clearly detectable expression levels in E3 and E5 limbs (Fig. 5B), and lower but still detectable levels of HGF/SF mRNA were present until the final time point tested on E14. Negative control reactions without primers or reverse transcriptase confirmed that the amplified product was not caused by DNA contamination. Thus, whole-mount in situ hybridization and RTPCR data reveal that $\mathrm{HGF} / \mathrm{SF}$ is expressed in the limbs before and during PCD of lumbar MNs.

\section{HGF/SF does not rescue MNs from cell death in response to limb bud removal}

Target-derived trophic factors play a central role in determining MN survival during development. Removal of the chick hindlimb bud (LBR) at E3, before axonogenesis, results in the near total loss of ipsilateral MNs by E8.0-E9.0 (Oppenheim et al., 1978; Caldero et al., 1998). Addition of CMX and trophic factors such as GDNF after LBR partially reverses this cell loss, increasing MN survival (Caldero et al., 1998). We tested the ability of $\mathrm{HGF} / \mathrm{SF}$ to prevent MN cell loss after LBR. LBR was performed on E3, followed by treatment with $5 \mu \mathrm{g} \mathrm{HGF/SF}$ or physiological saline solution on E4, E5, E6, and E7. Embryos were killed on E7.5, and the number of surviving MNs was counted in the LMC ipsilateral and contralateral to the LBR. Surprisingly, HGF/SF increased the number of surviving $\mathrm{MNs}$ on the contralateral side but had no effect on MN survival on the LBR (ipsilateral) side (Fig. 6A).

Because c-met expression appears between E4 and E5 in control embryos (Fig. 4), we examined whether the lack of response of developing MNs to $\mathrm{HGF} / \mathrm{SF}$ after LBR could be attributable to a loss of c-met expression caused by the loss of a putative limb-derived signal. LBR was again performed on E2, and embryos were allowed to develop until E5.5, the beginning of LBR- induced PCD. At this time the embryos were killed, and c-met expression was examined in lumbar spinal cord sections by in situ hybridization. We observed intense c-met expression on the side contralateral to the LBR (Fig. 6B), whereas the ipsilateral side exhibited greatly reduced c-met expression. Islet-1/2 staining revealed that the reduced c-met expression ipsilateral to the LBR was not caused by MN cell loss (Fig. 6D). Thus, it appears that some factor or factors other than HGF/SF present in the developing limb bud are required to induce c-met expression and subsequent $\mathrm{HGF} / \mathrm{SF}$ responsiveness.

Accordingly, we next asked whether a signal present in extracts from developing limb muscle (CMX) could be involved in inducing c-met expression. Once again, LBR was performed at E3, followed by addition of CMX $(150 \mu \mathrm{g})$ in ovo on E4 and E5. Embryos were then killed at E5.5. In situ hybridization performed on lumbar spinal cord sections from three embryos in five separate experiments using the c-met antisense probe revealed that CMX treatment restored intense levels of c-met expression in the ipsilateral LMC after LBR (Fig. 6C,D). Thus, some factor or factors present in developing limb muscle is required to induce c-met expression in MNs located in the lumbar LMC, which then allows them to respond to $\mathrm{HGF} / \mathrm{SF}$ and promote MN survival. Because continued treatment with $\mathrm{HGF} / \mathrm{SF}$ from E5 to E7 failed to promote MN survival (Fig. $6 A$ ), $\mathrm{HGF} / \mathrm{SF}$ is not likely to be the limb-derived factor needed for c-met expression.

Finally, to directly examine whether CMX could reinstate a biological survival response to HGF after LBR, HGF $(5 \mu \mathrm{g})$ was administered daily together with a nonsurvival-promoting dose of CMX (15 $\mu \mathrm{g})$ to LBR embryos on E4, E5, and E6, and MN survival was assessed on E7. Combinations of CMX plus HGF promoted survival of MNs on the side ipsilateral to the LBR (MN numbers, mean \pm SD: control saline, $4309 \pm 1011, n=4$; $\mathrm{CMX}, 4206 \pm 981, n=4 ; \mathrm{HGF}, 3815 \pm 1123, n=4 ; \mathrm{HGF}+$ CMX, $7597 \pm 888, n=5 ; p<0.01$ HGF vs HGF + CMX, $t$ test).

\section{DISCUSSION}

$\mathrm{HGF} / \mathrm{SF}$ is a multifunctional growth factor known to be involved in many early developmental systems, including development of skeletal muscle and the neural crest, as well as MN innervation of the limb. Several in vitro studies have also reported that HGF/SF is a muscle-derived MN survival factor for mammalian MNs (Ebens et al., 1996; Wong et al., 1997; Yamamoto et al., 1997). We have investigated the in vivo function and regulation of $\mathrm{HGF} / \mathrm{SF}$ and its receptor c-met in the spinal cord of the developing chick embryo.

Our results demonstrate that $\mathrm{HGF} / \mathrm{SF}$ selectively promotes the survival of lumbar MNs during the period of programmed cell death, both in vitro and in vivo. Experiments with in vitro cultures of chick MNs purified at the beginning of the period of naturally occurring cell death demonstrate that $\mathrm{HGF} / \mathrm{SF}$ promotes the survival of lumbar-derived but not thoracic- or brachial-derived MNs. Comparison of the survival response of MNs treated with $\mathrm{HGF} / \mathrm{SF}$ or CMX reveals that optimal concentrations of $\mathrm{HGF} / \mathrm{SF}$ support the survival of $\sim 60 \%$ as many motor neurons as CMX. This is in comparison with CNTF, BDNF, and GDNF, which save on the average 50, 90, and $70 \%$, respectively, of MNs compared with CMX. These results in the chick are in general agreement with previously published observations of rat $\mathrm{MN}$ cultures, where limb-innervating $\mathrm{MNs}$ are more sensitive to HGF/SF than thoracic MNs (Yamamoto et al., 1997). However, in cultured rat MNs, low concentrations of $\mathrm{HGF} / \mathrm{SF}$ promote the in vitro survival of both brachial and lumbar-derived MNs, and 

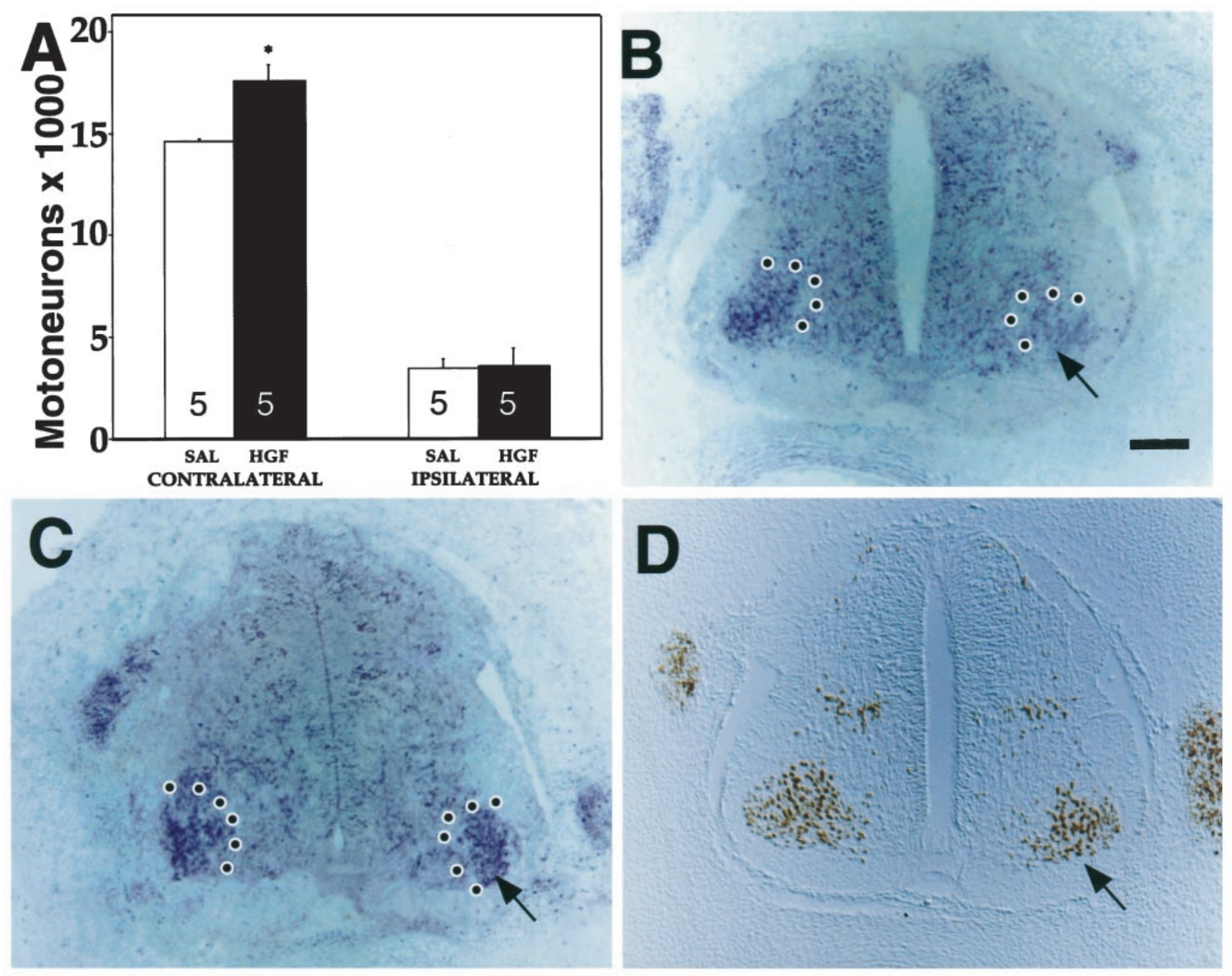

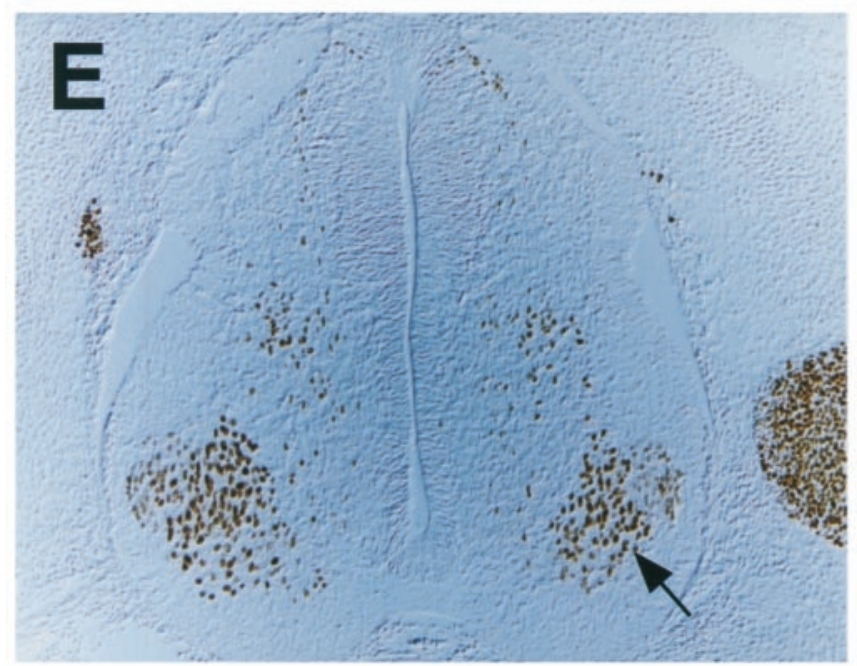

higher concentrations also promote the survival of thoracic MNs. In contrast, we observed in the chick that even high doses of HGF/SF support only the in vitro survival of lumbar-derived MNs. Treatment of MN cultures and embryos in ovo with CMX potentiated the effects of $\mathrm{HGF} / \mathrm{SF}$, suggesting that $\mathrm{HGF} / \mathrm{SF}$ is not the only muscle-derived factor that promotes lumbar $\mathrm{MN}$ survival. This potentiation may also reflect the role of musclederived signals in c-met expression (see below).
Figure 6. A, The number (mean $\pm \mathrm{SD}$ ) of lumbar MNs contralateral and ipsilateral to LBR on E7.5 after in ovo treatment with either HGF/SF $(5 \mu \mathrm{g})$ or physiological saline $(S A L) .{ }^{*} p<0.005$ ( $t$ test). $B-E$, In situ hybridization for c-met on E5.5 after LBR with either HGF/SF $(B)$ or CMX $(C)$ treatment. Dotted areas indicate the LMC ipsilateral (arrow) and contralateral to LBR. In $D$ and $E$, MNs in the ipsilateral (arrow) and contralateral LMC are immunolabeled (Islet1/2) after either $\operatorname{HGF}(D)$ or CMX $(E)$ treatment. Scale bar, $150 \mu \mathrm{m}$.

Although the anti-HGF antibody used here to block HGF/SF activity was made against rhHGF, it also blocked the activity of rcHGF/SF and significantly reduced the survival-promoting effects of CMX on cultured MNs. More importantly, in vivo treatment with anti-HGF selectively reduced the survival of lumbar MNs during the normal cell death period but was without effect on $\mathrm{MN}$ numbers when administered before that time. Additionally, as expected, anti-HGF treatment was without effect on 
brachial MNs either before or during the period of normal PCD. Accordingly, $\mathrm{HGF} / \mathrm{SF}$ is not required for the survival of either brachial or lumbar MNs before the onset of target-dependent PCD in these populations. This differs from sympathetic neurons that require $\mathrm{HGF} / \mathrm{SF}$ for survival early in development, before axonal outgrowth (Maina et al., 1998). Taken together, these anti-HGF experiments are consistent with the role of endogenous $\mathrm{HGF} / \mathrm{SF}$ as a physiologically relevant muscle-derived trophic factor for chicken lumbar MNs.

We have also demonstrated for the first time that exogenously supplied HGF/SF acts as a trophic factor for MN subtypes in vivo. In ovo treatment of chick embryos with optimal concentrations of $\mathrm{HGF} / \mathrm{SF}$ during PCD resulted in increased survival of lumbar but not brachial or thoracic MNs. Even within the lumbar LMC, not all MNs appear to express the HGF/SF receptor c-met and not all MNs are rescued from PCD. Previously, it has been difficult to assess the in vivo role of $\mathrm{HGF} / \mathrm{SF}$ on $\mathrm{MN}$ survival because HGF/SF or c-met null mutant mice die before the start of programmed cell death, and $\mathrm{HGF} / \mathrm{SF}$ is also required for myoblast migration to the developing limb (Schmidt et al., 1995; Uehara et al., 1995). Accordingly, the present data provide the first evidence that exogenous $\mathrm{HGF} / \mathrm{SF}$ can prevent the death of developing $\mathrm{MNs}$ in vivo and that reductions in endogenous $\mathrm{HGF} / \mathrm{SF}$ decrease $\mathrm{MN}$ survival. Although $\mathrm{HGF} / \mathrm{SF}$ can act on glial cells via the c-met receptor (Maina and Klein, 1999) and therefore could also indirectly affect $\mathrm{MN}$ survival in vivo, the in vitro data using highly enriched cultures of MNs show that $\mathrm{HGF} / \mathrm{SF}$ can act directly on MNs (Ebens et al., 1996; Yamamoto et al., 1997; present data) and does not promote the survival of non-MNs in our cultures. These in vitro data also indicate that $\mathrm{HGF} / \mathrm{SF}$ can act on MNs independent of its role in regulating the proliferation of secondary muscle fibers (Maina et al., 1996).

The in vivo and in vitro response of lumbar MNs to $\mathrm{HGF} / \mathrm{SF}$ treatment correlates with the observed expression pattern of the $\mathrm{HGF} / \mathrm{SF}$ receptor c-met. We observed that c-met is expressed in lumbar MNs during the period of PCD. The initial expression of c-met occurred between E4 and E5, as postmitotic lumbar MNs begin to innervate the leg. A similar temporal pattern of c-met expression has been observed in mouse embryo lumbar MNs (Ebens et al., 1996). Expression of c-met was not observed at any time in thoracic segments, and only a small region of c-met expression was consistently observed in the brachial LMC at E7 but not at other earlier or later ages. These brachial cells may represent a small MN pool capable of responding to $\mathrm{HGF} / \mathrm{SF}$ for a very short window of time and thus would not make enough of a contribution to the survival of the total brachial MN population to be detected in our assays. Because the c-met receptor is not detectable in brachial MNs before E7 (i.e., between E4 and E6), and because neither exogenous $\mathrm{HGF} / \mathrm{SF}$ administered in vivo beginning 2-4 d before the onset of normal brachial MN PCD on E7-E8 nor treatment with a neutralizing antibody against HGF/SF on either E5 or E7 affects brachial MN survival, $\mathrm{HGF} / \mathrm{SF}$ is not likely to be involved in the survival of brachial MNs either before or after the onset of PCD. The failure of $\mathrm{HGF} / \mathrm{SF}$ to rescue brachial MNs in vitro or in vivo may indicate that $\mathrm{HGF} / \mathrm{SF}$ is involved in axonal guidance or other developmental events of a subset of c-met-expressing brachial MNs (Ebens et al., 1996).

We have also demonstrated for the first time that HGF/SF mRNA is expressed in both upper and lower limbs during MN PCD. HGF/SF expression occurs early in chick development, initially appearing in Hensen's node at stage 3, in the developing neural tube at stage 8 , in notochord at stage 9 , and in floor plate up to stage 21 (Thèry et al., 1995). We and others have observed HGF/SF mRNA expression by in situ hybridization in the developing limb bud from stage 13 until stage 24 (Thèry et al., 1995). However, RT-PCR analysis revealed that detectable levels of $\mathrm{HGF} / \mathrm{SF}$ continue to be expressed in both upper and lower limbs throughout the time of PCD. Our data are in agreement with other studies reporting that $\mathrm{HGF} / \mathrm{SF}$ is expressed in chick and mouse limb but not axial muscle cells during PCD (Sonnenberg et al., 1993; Thèry et al., 1995; Andermacher et al., 1996).

In addition to their expression in the developing neuromuscular system, HGF/SF and c-met are also found in the brain of developing and adult rodents (Sonnenberg et al., 1993; Jung et al., 1994; Honda et al., 1995). In the chick embryo, we observed c-met expression in certain cranial motor nuclei as well as in visual relay nuclei of the midbrain and thalamus. Although we have not examined neuronal survival in these visual nuclei, exogenous treatment with $\mathrm{HGF} / \mathrm{SF}$ failed to rescue cranial MNs from PCD. $\mathrm{HGF} / \mathrm{SF}$ and c-met in these brain areas may play some other nonsurvival role (Ebens et al., 1996).

The chick embryo is an excellent model for identification of target-derived factors required for $\mathrm{MN}$ survival because of the ability to assay the survival-promoting activity of various factors in vivo after LBR or after axotomy. Removal of chick limb bud at E2.0, before axonogenesis, results in the near total loss of ipsilateral MNs by E8.0-E9.0 (Caldero et al., 1998). Addition of $\mathrm{HGF} / \mathrm{SF}$ in ovo after LBR promoted MN survival contralateral to the LBR, but failed to rescue MNs from cell death ipsilateral to the LBR. It seems likely that this was due to the fact that LBR is associated with the absence of c-met expression by MNs in the LMC of the ipsilateral lumbar spinal cord and that some unknown muscle-derived factor is required to induce c-met expression in lumbar MNs. In the absence of this signal, MNs fail to express c-met and are unresponsive to exogenous HGF/SF. In support of this, we have shown that CMX treatment induces c-met expression and combined treatment with CMX and HGF reinstates a survival response to $\mathrm{HGF}$ after LBR. Because the in vitro experiments with cultured lumbar MNs also deprive MNs of this putative muscle-derived signal, the rescue of MNs in vitro by $\mathrm{HGF} / \mathrm{SF}$ may appear counterintuitive. However, cultured MNs were taken on E5 when c-met expression is already present. Recently, a limb-derived signal has also been shown to be required for the expression of ETS transcription factors in chick embryo MNs (Lin et al., 1999).

Although a large number of trophic factors from different gene families have been shown to promote $\mathrm{MN}$ survival in vitro and in vivo (Oppenheim, 1996; Hanson et al., 1998), no single factor is able to rescue all MNs. Furthermore, genetic deletion of single trophic factors or their receptors results in only a partial (2030\%) loss of MNs (DiChiara et al., 1995; Liu et al., 1995; Moore et al., 1996; Cacalano et al., 1998). Taken together, these data indicate that the trophic requirement of developing MNs is complex and may depend on (1) their state of differentiation and developmental stage, (2) their CNS location and peripheral targets, and (3) their dependence on multiple factors from diverse sources. Although there is evidence consistent with each of these possibilities (Hughes et al., 1993; Mettling et al., 1995; Henderson, 1996; McKay et al., 1996; Zurn et al., 1996; Arce et al., 1998; Becker et al., 1998; Hanson et al., 1998), there have been no systematic attempts to examine whether MN subtypes, on the basis of their maturation, location, or synaptic targets, have distinct trophic factor requirements for survival. Our observations 
that a subset of lumbar but not other spinal or cranial somatic MNs exhibit a survival response to $\mathrm{HGF} / \mathrm{SF}$ in vitro and in vivo, together with the related evidence for cultured rat MNs (Yamamoto et al., 1997), provide the first evidence consistent with this idea. The molecular heterogeneity of MNs and their targets (Tsuchida et al., 1994) may reflect a similar heterogeneity in trophic factor responsiveness, in which competitive interactions only occur among MNs within a subpopulation that shares certain features in common such as developmental age (e.g., birth date), location (e.g., spinal vs cranial or limb vs nonlimb), or peripheral targets (e.g., dorsal vs ventral, flexor vs extensor, or fast vs slow muscles). If correct, this provides a new, more complex perspective on the regulation of MN survival that was hardly imaginable a few years ago but one that is consistent with the emerging picture for the trophic requirements of specific populations of peripheral sensory neurons (Snider, 1994).

\section{REFERENCES}

Andermacher E, Surani MA, Gherardi E (1996) Co-expression of the HGF/SF and c-met genes during early mouse embryogenesis precedes reciprocal expression in adjacent tissues during organogenesis. Dev Genet 18:254-266.

Arakawa Y, Sendtner M, Thoenen H (1990) Survival effect of ciliary neurotrophic factor (CNTF) on chick embryonic motorneurons in culture: comparison with other neurotrophic factors and cytokines. J Neurosci 10:3507-3515.

Arce V, Pollock RA, Phillipe J, Henderson C, deLapeyiere O (1998) Synergistic effects of Schwann- and muscle-cell derived factors on motoneuron survival involve GDNF and cardiotrophin-1 (CT-1). J Neurosci 18:1440-1448.

Ausubel FM, Brent R, ÇKingston RE, Moore DD, Siedman JG, Smith JA, Struhl K (1996) Current protocols in molecular biology. New York: Wiley.

Becker E, Soler R, Yuste V, Giné E, Sanz-Rodriguez C, Egea J, MartinZanca D, Comella J (1998) Development of survival responsiveness to BDNF, NT-3 and NT-4/5 but not to NGF in cultured motoneurons from chick embryo spinal cord. J Neurosci 18:7903-7911.

Birchmeier C, Gherardi E (1998) Developmental role of HGF/SF and its receptor, the c-met tyrosine kinase. Trends Cell Biol 8:404-410.

Burek M, Oppenheim R (1998) Cellular interactions that regulate cell death in the developing vertebrate nervous system. In: Cell death in diseases of the nervous system (Koliatsos V, Ratan R, eds), pp 145-180. Totowa, NJ: Humana.

Cacalano G, Farinás I, Wang S, Hugler K, Forgie A, Moore M, Armanini M, Philips H, Ryan A, Reichardt L, Hynes M, Davies A, Rosenthal A (1998) GFR $\alpha 1$ is an essential receptor component for GDNF in the developing nervous system and kidney. Neuron 21:53-62.

Caldero J, Prevette D, Mei X, Oakley RA, Li L, Milligan C, Houenou L, Burek M, Oppenheim RW (1998) Peripheral target regulation of the development and survival of spinal sensory and motor neurons in the chick embryo. J Neurosci 18:356-370.

Clarke PGH, Oppenheim RW (1995) Neuron death in vertebrate development: in vivo methods. Methods Cell Biol 46:277-320.

DiChiara T, Vejsada R, Acheson A, Suri C, Conover J, Friedman B, McCain J, Pan L, Stahl N, IP N, Kato A, Yancopoulous G (1995) Mice lacking the CNTF receptor, unlike mice lacking CNTF, exhibit profound motorneuron deficits at birth. Cell 83:313-322.

Ebens A, Brose K, Leonardo ED, Hanson MG, Bladt F, Birchmeier C, Barres BA, Tessier-Lavigne M (1996) Hepatocyte growth factor/scatter factor is an axonal chemoattractant and a neurotrophic factor for spinal motorneurons. Neuron 17:1157-1172.

Ensini M, Tsuchida T, Belting H, Jessell T (1998) The control of rostralcaudal pattern in the developing spinal cord: specification of motorneuron subtype identity is initiated by signals from paraxial mesoderm. Development 125:969-982.

Hamanoue M, Takemoto K, Matsumoto T, Nakamura K, Nakijima N (1996) Neurotrophic effects of hepatocyte growth factor on nervous system neurons in vitro. J Neurosci Res 43:554-556.

Hamburger V, Hamilton HL (1951) A series of normal stages in the development of the chick embryo. J Morphol 88:49-92.

Hanson M, Shen S, Wiemelt A, McMorris A, Barres B (1998) Cyclic
AMP elevation is sufficient to promote the survival of spinal motor neurons in vitro. J Neurosci 18:7361-7371.

Henderson CE (1996) Role of neurotrophic factors in neuronal development. Curr Opin Neurobiol 6:64-70.

Henderson C (1998) Programmed cell death in the developing nervous system. Neuron 17:579-585.

Hollyday M (1990) Organization of motor pools in the chick lumbar lateral motor column. J Comp Neurol 194:143-170.

Honda S, Kagoshima M, Wanaka A, Tohyama M, Matsumoto K, Nakamura T (1995) Localization and functional coupling of HGF and c-met receptor in rat brain: implication as a neurotrophic factor. Mol Brain Res 32:197-210.

Hughes RA, Sendtner M, Thoenen H (1993) Members of several gene families influence survival of rat motoneurons in vitro and in vivo. J Neurosci Res 36:663-671.

Johnson J, Yin Q, Prevette D, Oppenheim R (1995) Brain-derived proteins that rescue spinal motoneurons from cell death in the chick embryo. J Neurobiol 27:573-589.

Jung W, Castren E, Odenthal M, Vande Woude G, Ishii T, Dienes H, Lindholm D, Schirmacher P (1994) Expression and functional interaction of hepatocyte growth factor/scatter factor and its receptor c-met in mammalian brain. J Cell Biol 126:485-494.

Landmesser L (1978) The development of motor projection patterns in the chick hindlimb. J Physiol (Lond) 284:391-414.

Lin J, Saito T, Anderson DJ, Lance-Jones C, Jessell T, Arber S (1999) Functionally related motorneuron pool and muscle sensory afferent subtypes defined by coordinate ETS gene expression. Cell 95:393-407.

Liu X, Ernfors P, Jaenisch R (1995) Sensory but not motorneuron deficits in mice lacking NT-4 and BDNF. Nature 375:238-241.

Maina F, Klein R (1999) Hepatocyte growth factor, a versatile signal for developing neurons. Nat Neurosci 2:213-217.

Maina F, Casagranda F, Audero E, Simeone A, Comoglia PM, Klein R, Ponzetto C (1996) Uncoupling of Grb2 from the met receptor in vivo reveals complex roles in muscle development. Cell 87:531-542.

Maina F, Hilton MC, Ponzetto C, Klein DAM, Klein R (1997) Met receptor signaling is required for sensory nerve development and HGF promotes axonal growth and survival of sensory neurons. Genes Dev $3341-3350$.

Maina F, Hilton MC, Andres R, Wyatt S, Klein R, Davies AM (1998) Multiple roles for hepatocyte growth factor in sympathetic neurons development. Neuron 20:835-846.

Matise M, Lance-Jones C (1996) A critical period for the specification of motor pools in the chick lumbosacral spinal cord. Development 12:659-669.

Matsumoto K, Nakamura T (1997) Hepatocyte growth factor (HGF) as a tissue organizer for organogenesis and regeneration. BBRC 239:639-644.

McKay SE, Garner A, Caldero J, Tucker RP, Large T, Oppenheim RW (1996) The expression of trkB and p75 and the role of BDNF in the developing neuromuscular system of the chick embryo. Development 122:715-724.

Mettling C, Gouin A, Robinson M, El M'Hamdi H, Camu W, BlochGallego E, Buisson B, Tanaka H, Davies A, Henderson C (1995) Survival of newly postmitotic motoneurons is transiently independent of exogenous trophic support. J Neurosci 15:3128-3137.

Milligan CE, Oppenheim RW, Schwartz LM (1994) Motoneurons deprived of trophic support in vitro require new gene expression to undergo programmed cell death. J Neurobiol 25:1005-1016.

Moore M, Klein R, Farinas I, Sauer H, Armanini M, Phillips H, Reichardt L, Ryan A, Moore K, Rosenthal A (1996) Renal and neuronal abnormalities in mice lacking GDNF. Nature 382:76-79.

Mu X, Silos-Santiago I, Carroll S, Snider W (1993) Neurotrophin receptor genes are expressed in distinct patterns in developing dorsal root ganglia. J Neurosci 13:4029-4041.

Nakamura T, Nishizawa T, Hagiya M, Seki T, Simonishi M, Tashiro K, Shimuzu S (1989) Molecular cloning and expression of human hepatocyte growth factor. Nature 342:440-443.

Naldini L, Weidner KM, Vigna E, Gaudino G, Bardelli A, Ponzetto C, Narsimhan RP, Hartmann G, Zarnegar R, Michallopoulos GK (1991) Scatter factor and hepatocyte growth factor are indistinguishable ligands for the MET receptor. EMBO J 10:2867-2878.

Nieuwenhuys R, Ten Donkelar H, Nicholson C (1998) The central nervous system of vertebrates, Vol 3. Berlin: Springer.

Nishi R (1994) Neurotrophic factors: two are better than one. Science 265:1052-1053. 
Oakley R, Lefcourt F, Clary D, Reichardt L, Prevette D, Oppenheim R, Frank E (1997) Neurotrophin-3 promotes the differentiation of muscle spindle afferents in the absence of peripheral targets. J Neurosci 17:4262-4274.

Oppenheim RW (1981) Cell death of motorneurons in the chick embryo spinal cord. V. Evidence on the role of cell death and neuromuscular function in the formation of specific peripheral connections. J Neurosci 1:141-151.

Oppenheim RW (1991) Cell death during development of the nervous system. Annu Rev Neurosci 14:453-501.

Oppenheim RW (1996) Neurotrophic survival molecules for motoneurons: an embarrassment of riches. Neuron 17:195-197.

Oppenheim RW (1998) Programmed cell death. In: Fundamental neuroscience (Bloom FL, Landis SC, Roberts JL, Squire LR, Zigmond MJ, eds), pp 581-609. New York: Academic.

Oppenheim RW, Majors-Willard C (1978) Neuronal death in the brachial spinal cord of the chick is unrelated to loss of polyneuronal innervation in wing muscle. Brain Res 154:148-152.

Oppenheim RW, Chu-Wang I, Maderdrut JL (1978) Cell death of motorneurons in the chick embryo spinal cord. III. The differentiation of motorneurons prior to their induced degeneration following limb-bud removal. J Comp Neurol 177:87-112.

Oppenheim RW, Haverkamp LJ, Prevette D, McManaman JL, Appel SH (1988) Reduction of naturally occurring motorneuron death in vivo by a target-derived neurotrophic factor. Science 240:919-922.

Oppenheim RW, Prevette D, Haverkamp LJ, Houenou L, Yin Q, McManaman J (1993) Biological studies of a putative avian musclederived neurotrophic factor that prevents naturally occurring motorneuron death in vivo. J Neurobiol 24:1065-1079.

Oppenheim RW, Houenou LJ, Johnson JE, Lin LFH, Li L, Lo AC, Newsome AL, Prevette DM, Wang SW (1995) Developing motor neurons rescued from programmed and axotomy-induced cell death by GDNF. Nature 373:344-346.

Pfaff C, Kitner C (1998) Neuronal diversification: development of motor neuron subtypes. Curr Opin Neurobiol 8:27-36.

Prevette D, Wang S, Gould T, Novak K, Oppenheim R (1997) Hepatocyte growth factor promotes the survival of subpopulations of developing avian motoneurons in vivo and in vitro. Soc Neurosci Abstr 23:1157.
Schmidt C, Bladt F, Goedecke S, Brinkmann V, Zschlesche W, Sharpe M, Gheradi E, Birchmeier C (1995) Scatter factor/hepatocyte growth factor is essential for liver development. Nature 373:699-702.

Snider W (1994) Functions of the neurotrophins during nervous system development: what the knockouts are teaching us. Cell 77:1-20.

Sockanathan S, Jessell T (1998) Motor neuron-derived retinoid signaling specifies the subtype identity of spinal motor neurons. Cell 94:503-514.

Sonnenberg E, Meyer D, Weidner KM, Birchmeier C (1993) Scatter factor/hepatocyte growth factor and its receptor, the c-met tyrosine kinase, can mediate a signal exchange between mesenchyme and epithelia during mouse development. J Cell Biol 123:223-235.

Tanabe H, Jessell T (1996) Patterning the vertebrate nervous system. Science 274:1115-1122.

Thèry C, Sharpe MJ, Batley SJ, Stern CD, Gherardi E (1995) Expression of $\mathrm{HGF} / \mathrm{SF}, \mathrm{HGF} 1 / \mathrm{MSP}$, and c-met suggests new functions during early chick development. Dev Genet 17:90-101.

Tokumoto M, Gong Z, Tsubokaura T, Hew C, Uyemura K, Hotta Y, Okamoto M (1995) Molecular heterogeneity among primary motoneurons in embryonic zebrafish. Dev Biol 171:578-589.

Tsuchida T, Ensini M, Morton SB, Baldassare M, Edlund T, Jessell TM, Pfaff SL (1994) Topographic organization of embryonic motor neurons defined by expression of LIM homeobox genes. Cell 79:957-970.

Uehara Y, Minowa O, Mori C, Shiota K, Kuno J, Noda T, Kitamura N (1995) Placental defect and embryonic lethality in mice lacking hepatocyte/scatter factor. Nature 373:702-705.

Weidner KM, Sachs M, Birchmeier W (1993) Evidence for the identity of human scatter factor and human hepatocyte growth factor. Proc Natl Acad Sci USA 88:7001-7005.

Wong V, Glass D, Arriaga R, Yancopoulas G, Lindsay R, Conn G (1997) HGF promotes motoneuron survival and synergizes with CNTF. J Biol Chem 272:5187-5191.

Yamamoto Y, Livet J, Pollock R, Garces A, Arce V, deLapeyriere O, Henderson C (1997) Hepatocyte growth factor is a muscle-derived survival factor for a subpopulation of embryonic motor neurons. Development 124:2903-2913.

Zurn A, Winkel L, Menoud A, Djasali K, Aebischer P (1996) Combined effects of GDNF, BDNF and CNTF on motoneuron differentiation in vitro. J Neurosci Res 44:133-141. 